\title{
An Investigative Study on Perceived Indoor Air Quality During COVID-19 Lockdown in India
}

\author{
Tanya Kaur Bedi ${ }^{1}$ (D) Shankha Pratim Bhattacharya ${ }^{1}$
}

Received: 12 October 2020/Accepted: 24 May 2021/Published online: 18 July 2021

(C) The Institution of Engineers (India) 2021

\begin{abstract}
The air we breathe is a worldwide concern, especially in developing countries like India. Recently, the coronavirus pandemic resulted in restricted activities which showed noteworthy improvement in ambient air. As it hassled people to reach home, corporations began work from home schemes. Conforming to WHO, coronavirus is airborne as transmission cannot be disregarded in crowded and inadequately ventilated indoor spaces. A high-density population spending more time indoors raises questions on existing indoor requirements of accommodating a healthy long-duration inhabitation. Indoor time is also likely to extend with higher than before acceptance to online learning, entertainment, and shopping. Even though air pollution is mostly thought of as an outdoor concern, studies suggest that the air indoors can be contaminated as well, and sometimes even more than the air outside. India has shown growth in building-related illness, whereas lack of specific standards and limited research raises a concern. The countrywide lockdown to control the coronavirus situation in India has brought overwhelming improvement in the air quality due to restricted anthropogenic activities. This study is based on a pan India survey and ambient air quality data by the central pollution control board to understand the change in outdoor air pollution and indoor air quality perception before and during the lockdown in 205 cities categorized as per government guidelines. It also aims to understand the relationship between various parameters and perceived indoor air quality. Even though the COVID-19 pandemic has bought unprecedented health
\end{abstract}

\footnotetext{
Tanya Kaur Bedi

tanyabedi@iitkgp.ac.in

Indian Institute of Technology, Kharagpur, India
}

and economic crisis, the pandemic may act as a promoter for healthy and sustainable indoor environments.

Keywords Air pollution - Indoor air quality · IAQ · COVID-19 pandemic $\cdot$ India $\cdot$ Lockdown

\section{Introduction}

When the World Health Organization (WHO) affirmed the COVID-19 spreading a pandemic, people all over the world rushed to reach home. The virus has made a massive effect on our professional, as well as personal lives. According to WHO, coronavirus is airborne in crowded and inadequately ventilated indoor spaces, where the shortrange aerosol transmission cannot be disregarded [1]. As a reaction, questions arise on how architects and planners possibly will put in new ideas or upgrade existing spaces to the growing indoor requirements. Extensive research is required for the countless unanswered questions. Following the current scenario, post-pandemic future houses will possibly need to accommodate workspaces and thus adapt to long-duration inhabitation. Modular construction, planted balconies, prefabricated components, adaptive reuse, and touch avoiding smartphone control systems are a few talked-about technologies. These may also include automatic cleaning and sanitizing, which do not involve a high additional cost. After the mandatory self-isolation and spending more time indoors due to the lockdown, an approach to improve indoors through strategies to achieve better ventilation and sunlight, less toxic materials, and integration of natural materials and plant life is needed. In this situation, significance must be given to improved designs using large windows, green balconies/rooftops, skylights, and courtyards to avoid building-related illness 
(BRI) and enhance living conditions. There will be exceptional efforts to contemplate every single place that has been touched and maybe act as an infection source. Similar to eliminating ornamentation to facilitate cleanliness and hygiene, modern designers are likely to apply further cleaning tactics in post-pandemic architecture. It is expected that indoor time will have higher than ever acceptance due to distance learning, online entertainment, and online shopping. With work from home (WFH) becoming common, post-pandemic spaces will witness a transformation. As a matter of fact, an average person breathes about 25,000 times a day, most of the time indoors [2]. Breathing in high volumes of stale or contaminated air, particularly in buildings without proper cross-ventilation and daylight, raises a concern.

On 11th March 2020, WHO declared the spread of the COVID-19 virus, which originated in Wuhan city of China, a pandemic. In response to this situation, several nations instigated the lockdown rules by halting daily activities and securing boundaries. Similarly, the Government of India organized a countrywide lockdown of 21 days on 24th March 2020. This was the world's largest lockdown which limited the movement of entire 1.3 billion residents of India. It was initiated strategically after a 14-h curfew on 22nd March, the order decreased the daily activities in industries and relentlessly reduced road and air traffic. Even though the usefulness of lockdown in controlling the coronavirus spread is yet to be known, it has undeniably generated substantial improvement in the natural environment. As per a Central Pollution Control Board (CPCB) report published after the lockdown, the average particulate matter (PM) in India has reduced by approximately $52 \%$ in the lockdown period [3]. This study compares the air quality before and during the lockdown period for cities surveyed collectively with the perception of inhabitants on their consequent indoor air quality improvement. It also tried to introspect the understanding of city dwellers and their concerns towards their indoor environment. The air quality index (AQI) came down to 44\%, 33\%, 29\%, 32\%, and $15 \%$ in north, south, east, western, and central India, respectively. Also, as evident from Fig. 1, NASA satellites detected a 20-year dip in the aerosol levels in India.

Total pollution load in India using air quality zonal modelling reveals that there were $460,000 \mathrm{~km}^{2}$ areas under a high concentration of pollutants about a month before the pandemic lockdown restrictions which declined to almost half $230,000 \mathrm{~km}^{2}$ during the lockdown period. Contrastingly, areas under low pollutants concentration beforehand increased from 740,000 to $990,000 \mathrm{~km}^{2}$ denoting improved air quality [5]. A recent study on air quality in 46 cities throughout India finds that particulate matter concentrations reduced by approximately $23 \%, 16 \%$, and $32 \%$ in small, medium, and large cities, respectively. The outcomes further put forward the fact that the lockdown's impact on the quality of air was not homogenous throughout the country which was certainly attributable to varying background contributions. The average concentrations of particulate matter and nitrogen dioxide were found higher in metro cities than smaller cities and towns [6]. Another study throws light on the pollutant levels from the lockdown
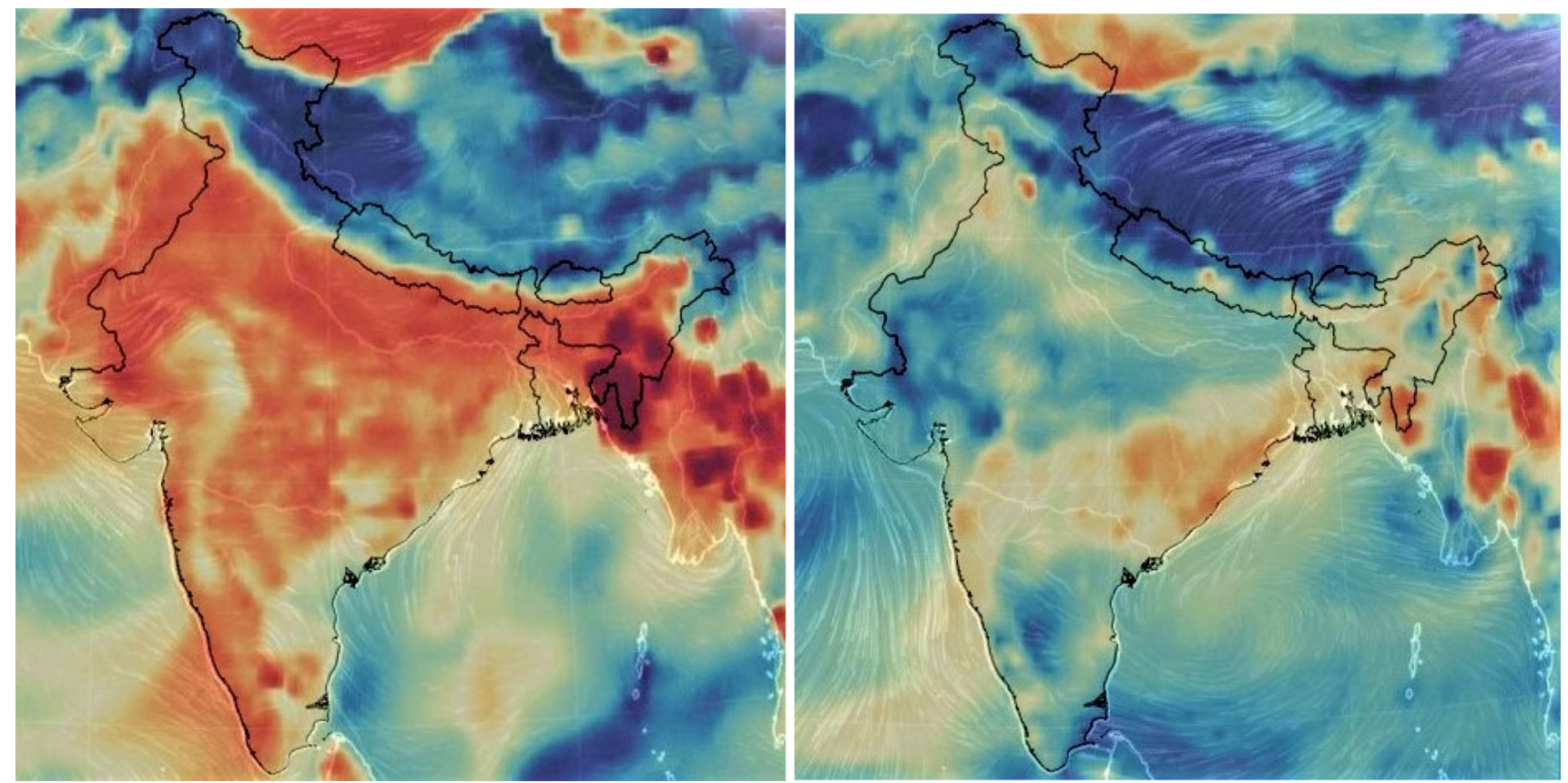

Fig. 1 Particulate matter in March 2019 (left) and March 2020 lockdown period (right) [4] 
period in 2020 compared to the same period in 2019 in 39 different cities in India including ten of the world's twenty most polluted cities of 2019. During the lockdown, only $15 \%$ of cities fall under the 'Unhealthy' AQI category (151-200) while in $2019,56 \%$ of the cities were in that category. The most substantial drop was witnessed for nitrogen dioxide and carbon monoxide which are predominantly related to road traffic emissions [7]. Globally, the coronavirus outbreak is associated with both indoor and outdoor air pollution and co-morbidities of human beings [8]. Since outside air is undoubtedly a key contributor to indoor air, the changes in the air in the lockdown period can also provide an insight into the achievable indoor environment through ventilation, activity restriction, etc.

\section{Indoor Air Quality (IAQ)}

Dissimilar to the air outside, indoor air is re-circulated continuously in the built environment, making it vulnerable to entrap pollutants. Various building materials, finishing materials, furniture, carpets, etc., are potential sources of these pollutants or contribute to trapping them. The US Environmental Protection Agency (EPA) defines IAQ as follows: "Indoor Air Quality refers to the air quality within and around buildings and structures, especially as it relates to the health and comfort of building occupants" [9]. The major causes of increasing indoor pollution comprise sealed building envelopes, improper location of exhausts/vents. Inadequate ventilation also facilitates unhygienic conditions promoting the growth of biological contaminants like fungi and bacteria. Lack of daylight and air-circulation in buildings is associated with respiratory problems, dermal allergies, and diminishing productivity. Living in damp buildings is linked with the possibility of an increase in asthma risk by up to $40 \%$, and lack of sunlight might lead to sadness as well [10]. Generally, it is challenging to precisely point out to what extent poor IAQ can affect health, as information regarding the association between the two is inadequate. Some common pollutants include $\mathrm{NO}_{2}, \mathrm{CO}$, VOCs, RSPM, $\mathrm{SO}_{2}, \mathrm{O}_{3}, \mathrm{CH}_{2} \mathrm{O}$, asbestos, bacteria, and viruses. High exposure to some contaminants like carbon monoxide (CO) can cause instant death. Since poor IAQ has a direct relation with several illnesses, it should be considered a public health issue.

\section{Concept of Perceived Indoor Air Quality}

Post-occupancy evaluation is a practice to evaluate buildings after they have been occupied as a guide for future buildings and as feedback to learn about occupant comfort/satisfaction/productivity. Surveys, observations, questionnaires are tools used that can be used alone or in combination in the process. Building occupants are a valuable information source about indoor air quality and its health effects. Although it appears logical that the quality of air depends upon the existence of specific components and their quantities, the inhabitant's respiration experience is also a good indicator of air quality as human senses are sensitive to nearly half-million chemical compounds. If the building occupants are satisfied with the air quality, it is said to be good, and if they are unsatisfied, it is of poor quality. Thus, it is partly helpful in understanding air quality [11]. Although there are no standard methods to survey building occupants, several methods of evaluation have been developed since 1981, the first by the National Academy of Sciences Committee on Indoor Pollutants [12] after sick building syndrome (SBS) was introduced in the 1980s by WHO as an umbrella of symptoms believed to be associated with the degraded indoor environment of a building [13].

According to the American Society of Heating, Refrigerating and Air-Conditioning (ASHRAE), a building is classified to be sick in case $20 \%$ or more of its inhabitants complain about issues like headache, irritation, etc., and feel better when moved out. It lists irritation in the eyes, nose, and throat, headache, dry mucous membranes and skin, fatigue, hypersensitivity, high frequency of airway infection, cough, nausea, and dizziness as building-related illnesses [14]. For this study, a thorough literature review was performed using the key terms: indoor air quality questionnaire, post-occupancy evaluation, occupant satisfaction, indoor environment evaluation, etc. Selected proceedings and papers were screened by type of evaluation, objectives, the number of applications, questionnaire structure, investigated topics, time to complete, types of questions/answers, and distribution and gathering approaches. Also, indoor air quality questionnaires developed for use in field studies by leading associations like ASHRAE, U.S. Green Building Council (USGBC) and Chartered Institution of Building Services Engineers (CIBSE) which have ample features in common were referred. As peoples' perceptions of indoor air quality reported based on questionnaires have frequently been used as a subjective indicator of IAQ, the questions considered in the survey are centred around the respondents' sensory perceptions [15]. Techniques like logic branching and layering are implied to reach a high level of confidence in outcomes. These environmental inventory questionnaires can be used to systematically identify factors affecting indoor air quality and exposure-response relationships [16].

\section{Indoor Air Quality and Its Post-Pandemic Importance}

From the past few decades, indoor air pollution has now become a concern in India, approximately, $30-40 \%$ of Indian public lives in urban areas. Thus, it can be said that 
a large part of the country's population is unprotected from the world's highest polluted air [17]. Urban areas buildings are certainly exposed to this scenario; occupants are therefore battling the air outside and also the air indoors. As per the periodic labour force survey (PLFS) by National Sample Survey Office (NSSO), out of $168 \mathrm{~h}$ in a week, a person spends typically about $48-56 \mathrm{~h}$ at the workplace in normal conditions [18]. Thus, an average working adult in India usually spends around $8 \mathrm{~h}$ at the workplace and $13 \mathrm{~h}$ at home [19], much time breathing air inside homes.

\section{Growth in Work from Home (WFH) Post-Pandemic}

The pandemic has conveyed a sense of gratefulness for our homes, especially which can protect us from infections and efficiently provide quarantine arrangements. The lockdown period mandated people to work from home by their employers. The leading Indian multinational information technology companies quickly moved almost $90 \%$ of their employees to an operative model called Secure Borderless Workspaces following the decision to WFH, this system is expected to run till the year 2025 [20]. The companies could ask $75 \%$ of their vast global workforce to WFH, up from the current industry average of $20 \%$. Other companies are in the offing to follow the working models adopted by the leading MNCs, avoiding to drop the human capital competitive advantage [21]. The expectation is that WFH will continue for many, even after this period ends, and restrictions uplift. More attention to WFH arrangements of the employees will be transforming the spatial organization of homes. While it is an advantage to several employees, reduction in traffic pollution is another boon; nevertheless, the long-term influence of this change is unclear and needs further exploration.

\section{Lack of Specific Standards and Limited Research on Residential IAQ}

The standards formulated for pollutant concentration are to protect the environment and human health from adverse effects. In the Air (Prevention and Control of Pollution) Act of 1981, The National Ambient Air Quality Standards (NAAQS) are set by the Central Pollution Control Board (CPCB). They are pertinent throughout the nation [22]. The national standards are for outdoor air and not for the indoors. Air quality, including the inside of homes, is now a question of environmental and human health same as ambient air quality and exposure. The number of studies conducted on IAQ in India or other countries varies in the selection of building typology. Observantly, most researchers have focused mainly on public/administrative buildings like office spaces and institutions. As a matter of fact, conducting surveys, field tests, questionnaires and monitoring are practically more effortless in institutions and companies when compared to private buildings or residences. Since certain agreements and arrangements can manage these spaces, it is relatively simple to restrict troubling activities and obtain a controlled environment. On the other hand, private residences are inaccessible except by invitation of the occupant, which is challenging. Consequently, the numbers of studies on housings are relatively sporadic.

\section{Building-Related Illness (BRI)}

Unmistakably in the case of indoor pollution in India, which is a silent killer, pollutants not even visible to the naked eye are entering human bodies. It results in not just breathing difficulty and discomfort, but with severe health impacts like viral infections and lung cancer [23]. The extent of the occupational health crisis can be understood by the statistics in the 2016 report published by WHO, which states that indoor air pollution in India accounts for 2 million deaths every year. As estimated by a study conducted in Indira Gandhi Institute for Development Research, the national burden of disease in India from indoor air pollution shows no less than 1 lakh children below five years of age died in the year 2016 [24]. The results are also published in the WHO report entitled 'Air Pollution and Child Health' [25].

\section{Study Objectives and Methodology}

\section{Objectives}

The first objective of this study is to apprehend the change in ambient air quality before and during the COVID-19 lockdown period in India in association with the indoor air quality experience of the city dwellers. Secondly, it tries to comprehend the city dweller's understanding of IAQ and its relationship with various related parameters in small, medium, and large cities (Fig. 1).

\section{Methodology}

The study is based on primary data collected through an online questionnaire survey, conducted in early April 2020 during the first lockdown. Ambient air quality data from the central pollution control board are used to compare with the perceived IAQ before and during the lockdown. The statistical analysis uses Microsoft Excel 2016 version, and the maps displaying geographical location have been generated using 3D maps in Excel. Figure 2 depicts the 


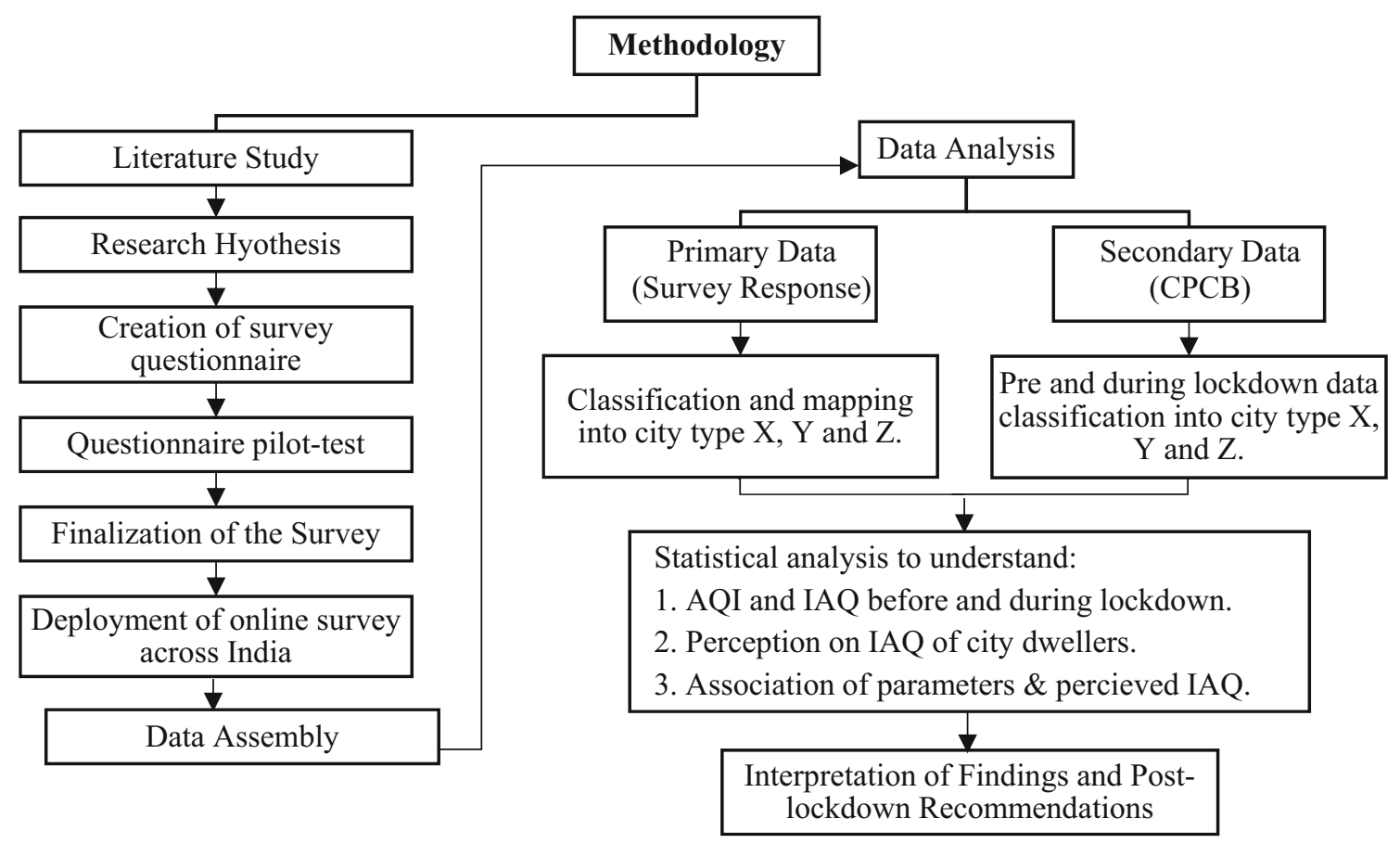

Fig. 2 Flow chart of methodology adopted for the study

methodology followed for the study. The subsections detail out data collection and processing.

Primary Data—Online Survey

The 10-day survey was conducted from 6 to 15 April 2020 during the first 21-day lockdown. The questionnaire had 30 questions in total and was designed to capture detailed information on the key aspects of IAQ. To tackle subjectivity bias due to no prior knowledge, the survey begins with a salutation and a short to the point overview of IAQ in a very simple day to day language: "Hello! Do you know we spend more than $80 \%$ of our time inside buildings breathing in air which may be polluted? This survey is about the air inside your home and its quality in terms of gaseous and physical contamination which may result in adverse health impacts". To minimize preconception, the survey is facilitated by using a partly photo-questionnaire survey and layered questions technique which assures reliability and avoids bias in responses. The questions were divided into three thematic sections: the first cover several aspects related to perceived IAQ, residence details, and drivers of air quality. The second section looks into the health impact of IAQ and personal habits. Questions from the third section focus on the respondent's attitude towards the significance of IAQ. The questionnaire consisted of mostly Likert scale and multiple-choice questions offering respondents the possibility to choose the most suitable option.

The survey was distributed as an invitation to participate in the study through email and various social platforms to maximize reach. The survey reached 205 cities/towns in India, distributed all over the country. Concerning the distribution by geographic origin, uniform responses cannot be expected from each city; thus, some cities may be over-represented, and others might be under-represented. Thus, for the study, the cities are grouped as per the Ministry of Finance Government of India, classification system into three main categories, which are $\mathrm{X}, \mathrm{Y}$, and $\mathrm{Z}$ cities, also commonly referred to as Tier-1, Tier-2, and Tier-3 cities [26]. Figure 3 depicts the distribution of survey in Indian cities. The circle size in city category-specific maps illustrates the response size, the bigger the circle, the more significant the number of responses from that particular area. Among the total of 205 cities surveyed, tier-1 or $\mathrm{X}$ cities are eight in number, which constitutes all the tier-1 cities, namely Ahmedabad, Bangalore, Chennai, Delhi, Hyderabad, Kolkata, Mumbai, and Pune. The rest responses include 65 tier-2/Y-cities and 132 tier-3/Z-cities.

\section{Secondary Data—Central Pollution Control Board}

The CPCB executes the monitoring systems nationwide. Air quality in India is monitored by Continuous Ambient Air Quality Monitoring Stations (CAAQMS). Ambient air 


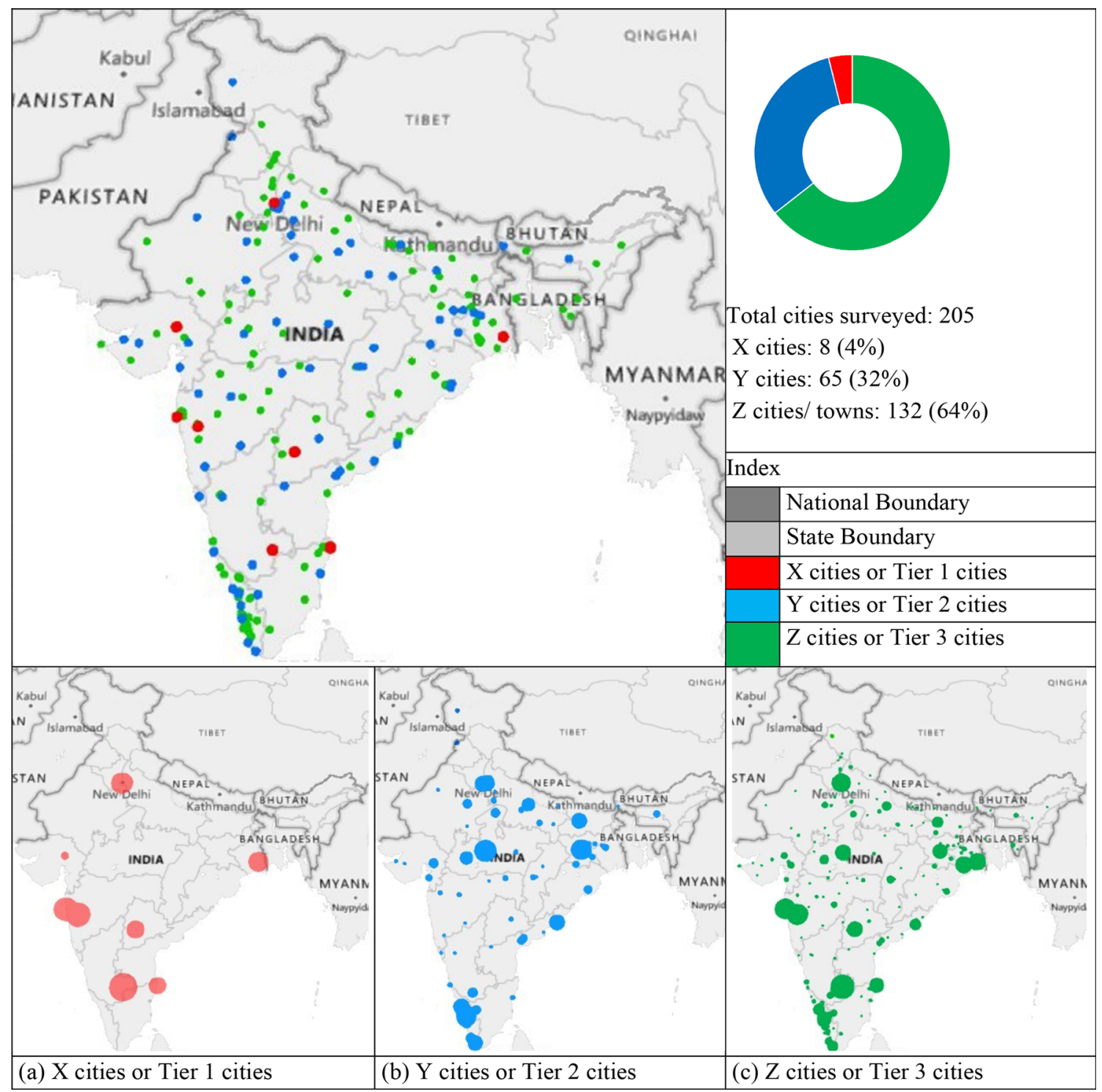

Fig. 3 Distribution of survey response-collectively and separately for each city category

quality monitoring is also carried out under the National Air Quality Monitoring Program (NAMP). Initiated in the year 1984, NAMP significantly expanded, it was initially called the National Ambient Air Quality Monitoring (NAAQM). The monitoring stations are present in 19 out of 29 states [27]. Table 1 depicts details of all the monitoring stations in India till February 2020, maintained by the Central Pollution Control Board. To study the variations in air quality before and during the lockdown period, the air quality data for the pre-lockdown period (1st March to 21st March 2020-21 days) and lockdown period (25th March to 14th April 2020-21 days) have been obtained in terms of AQI of the city for each day. The AQI values were attained from the Central Pollution Control Board (CPCB) online portal under the Ministry of Environment, Government of India. AQI uses five pollutants, namely PM2.5,
PM10, $\mathrm{NO}_{2}, \mathrm{SO}_{2}, \mathrm{NH}_{3}, \mathrm{CO}$, and $\mathrm{O}_{3}$ as indices. The average value of pollutant concentration is converted to an index, commonly known as Air Quality Index (AQI), expressed as: "Index $=$ (Pollutant Concentration / Pollutant Standard Level) $\times 100$ ". Thus, an index value of 100 would mean a critical stage where pollutant concentration is equal to the standard value. AQI ranging from 0 to 50 is said to be good, and the range of 51-100 is considered satisfactory, whereas AQI range of 101-200 (moderate) can cause breathing discomfort to people with lungs, asthma, and heart diseases. AQI from 201 to 300 comes under the poor category and can cause breathing discomfort to most people on prolonged exposure. A very poor AQI range of 301-400 can cause respiratory diseases, and the severe range of 401-500 mildly affects healthy people and severely impacts those with existing health conditions [28]. 
Table 1 Monitoring stations in the Indian states [27]

\begin{tabular}{|c|c|c|c|c|c|c|c|c|c|}
\hline State/UT & CAAQMS & Cities & NAMP & Cities & State/UT & CAAQMS & Cities & NAMP & Cities \\
\hline Delhi & 38 & 1 & 10 & 1 & Jharkhand & 1 & 1 & 10 & 7 \\
\hline Uttar Pradesh & 26 & 13 & 77 & 24 & Meghalaya & 1 & 1 & 10 & 7 \\
\hline Haryana & 24 & 23 & 5 & 3 & Arunachal Pradesh & 0 & 0 & 2 & 2 \\
\hline Maharashtra & 22 & 10 & 80 & 27 & Chhattisgarh & 0 & 0 & 13 & 5 \\
\hline Karnataka & 20 & 11 & 30 & 17 & Dadara and Nagar Haveli & 0 & 0 & 3 & 2 \\
\hline Madhya Pradesh & 16 & 15 & 39 & 14 & Daman Diu & 0 & 0 & 3 & 2 \\
\hline West Bengal & 14 & 6 & 79 & 40 & Goa & 0 & 0 & 17 & 17 \\
\hline Rajasthan & 10 & 8 & 39 & 8 & Himachal Pradesh & 0 & 0 & 25 & 14 \\
\hline Punjab & 8 & 8 & 47 & 34 & Jammu & 0 & 0 & 3 & 1 \\
\hline Kerala & 7 & 6 & 28 & 11 & Kashmir & 0 & 0 & 4 & 2 \\
\hline Bihar & 6 & 3 & 8 & 7 & Lakshadweep & 0 & 0 & 1 & 1 \\
\hline Telangana & 6 & 1 & 25 & 11 & Manipur & 0 & 0 & 1 & 1 \\
\hline Andhra Pradesh & 5 & 5 & 72 & 16 & Mizoram & 0 & 0 & 11 & 4 \\
\hline Gujarat & 5 & 5 & 24 & 7 & Nagaland & 0 & 0 & 4 & 2 \\
\hline Tamil Nadu & 5 & 2 & 31 & 8 & Pondicherry & 0 & 0 & 6 & 2 \\
\hline Odisha & 2 & 2 & 33 & 16 & Sikkim & 0 & 0 & 9 & 8 \\
\hline Assam & 1 & 1 & 23 & 13 & Tripura & 0 & 0 & 2 & 1 \\
\hline Chandigarh & 1 & 1 & 5 & 1 & Uttarakhand & 0 & 0 & 8 & 6 \\
\hline
\end{tabular}

Mean values of 21 days of the pre-lockdown and during the lockdown period have been calculated for comparative analysis.

\section{Analysis and Results}

In this study, the AQI from the national air quality monitoring stations across various Indian cities for the 21-day pre-lockdown and 21-day during-lockdown period is analysed. Also, the occupant perceptions about IAQ were assessed through online questionnaires and have also been compared to the ambient air. This comparison of the data aids in understanding how the lockdown has brought about a change in the indoor environments as well. A total of
1015 survey participants belong to 205 cities. Among these, $\mathrm{X}, \mathrm{Y}$, and $\mathrm{Z}$ cities account for 355, 388, and 272 responses, respectively. In the survey questionnaire's last section, besides providing their location, participants were requested to state the age group they belonged to and gender.

To describe the sample on which the survey is based, it is imperative to note that $41 \%$ of the participants are women, consistent with a gender balance. When analysing this dimension further, the proportion of women amounts to $44 \%$ for $\mathrm{X}$-cities, while $43 \%$ and $37 \%$ for $\mathrm{Y}$ and $\mathrm{Z}$ cities. When looking explicitly at the age of survey participants, it emerges that the most represented age group is 25-35 years, accounting for almost 50\% of the total responses for all three categories. Overall, age 18-45 years
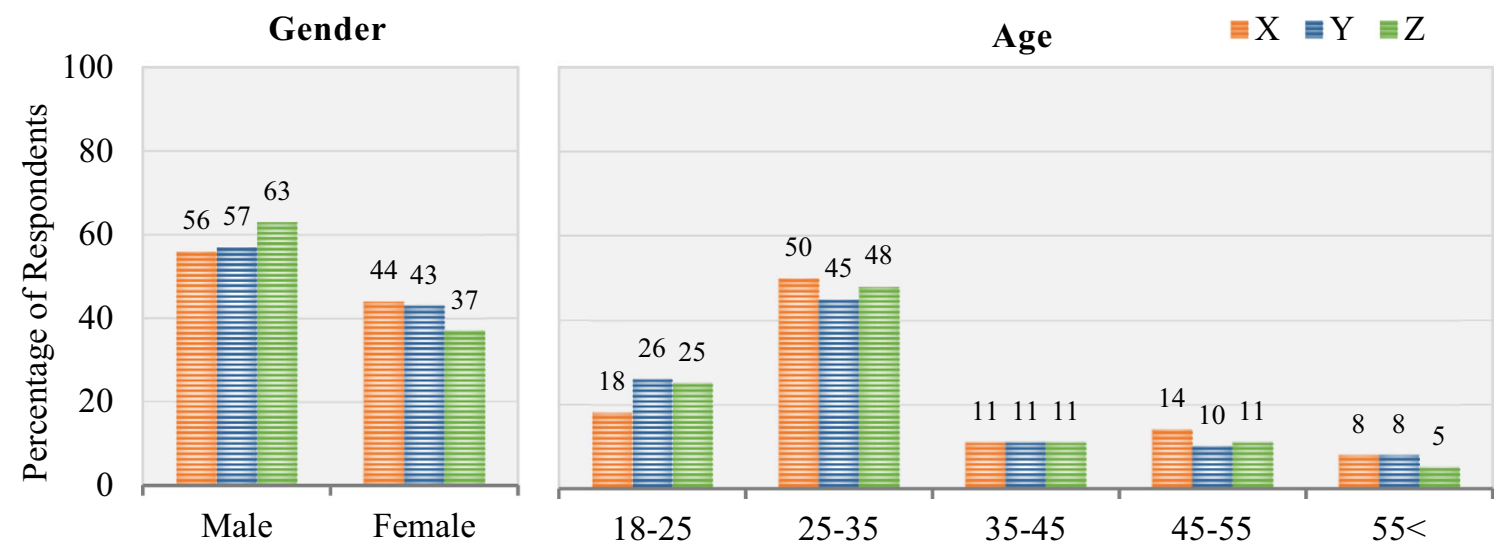

Fig. 4 Breakdown of respondents by gender and age 

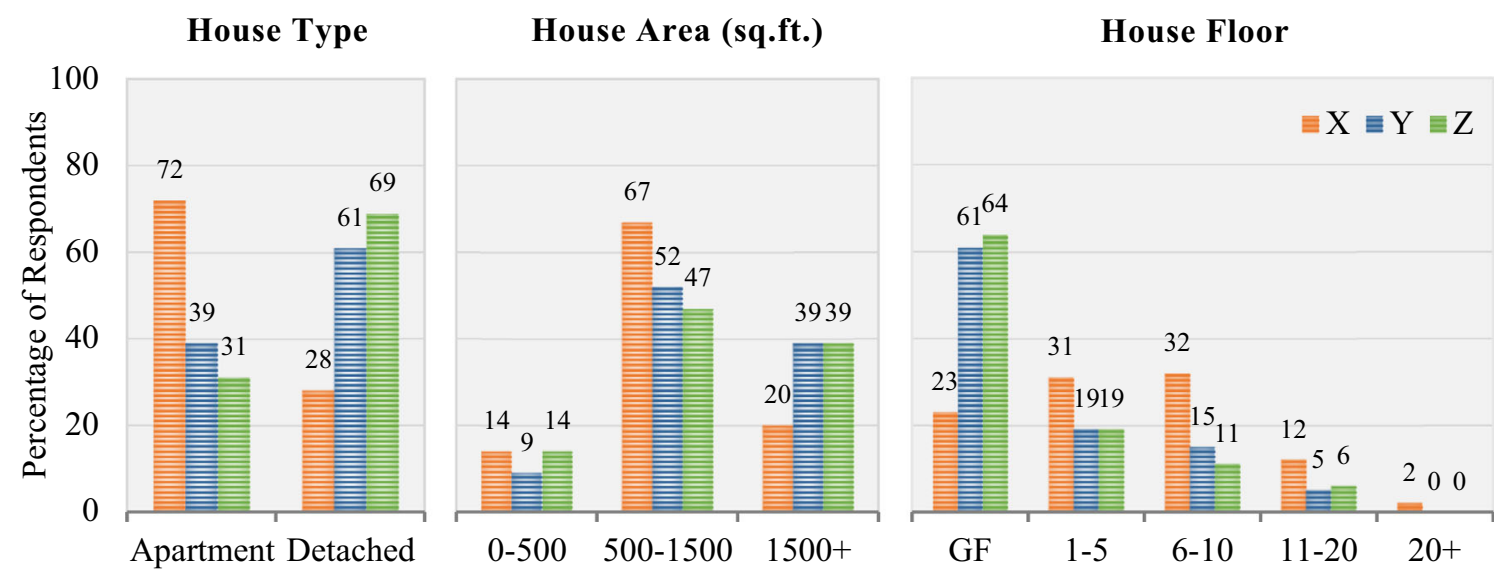

Fig. 5 Breakdown of respondents by house type, area and floor

represent nearly two-thirds of the total responses. Figure 4 illustrates the breakdown of respondents by gender and age.

Further, as shown in Fig. 5, 72\% of respondents live in apartments in $\mathrm{X}$-cities, while a majority of participants reside in detached units in $\mathrm{Y}$ and $\mathrm{Z}$ cities. The maximum representation is of houses of the area ranging from 500 to 1500 sqft for all the cities, which is the average built-up area of Indian residences. But in $\mathrm{Y}$ and $\mathrm{Z}$ cities, almost $40 \%$ of the respondents belong to homes larger than 1500 sqft. Less than $500 \mathrm{sqft}$ is the least represented house area, whereas in terms of floor number, $61 \%$ and $64 \%$ of participants live on the ground floor in $\mathrm{Y}$ and $\mathrm{Z}$ cities. Contrastingly, $63 \%$ of X-city respondents are from level 1-10. Altogether, X-city participants mostly belong to apartments of 500-1500 sqft on floor 1-10; whereas, in $\mathrm{Y}$ and $\mathrm{Z}$ cities, maximum participation is from detached houses with ground/first floor of $500-1500+$ sqft. This residential division clearly depicts the housing scenario of Indian cities where the densely populated and highly developed tier-1 cities have more high-rise buildings with less floor space compared to the less developed towns and cities (Fig. 6).

\section{Ambient Air Quality, Ventilation, and IAQ Perception Before and During Lockdown}

In this section, change in perceived IAQ before and during the lockdown period has been analysed along with ambient air quality for India, $\mathrm{X}, \mathrm{Y}$, and $\mathrm{Z}$ cities separately. The participants rated the IAQ at their home before and during the lockdown period from 1 to 5 , where 5 means excellent and 1 stands for very poor IAQ. Responses were analysed by descriptive statistics via histograms to tabulate the categorical data for visual analysis as shown in Fig. 6.

Metro cities, having a very high population density, show remarkable air quality improvement in the lockdown period [29]. When the surveyed cities are grouped into tier$1(\mathrm{X})$, tier-2 $(\mathrm{Y})$, and tier-3 $(\mathrm{Z})$ cities, it is observed that with a decrease in air pollution in the lockdown period, IAQ perception has shown a similar pattern of improvement. From the pre-lockdown to lockdown period, there is approximately a $33 \%$ increase in cities with good/satisfactory air quality. Also, in the course of the lockdown, none of the cities come into the category of severe AQI. Since the improvement in air quality was immense and immediate, it can be implied that the pollution is caused by daily happenings and not any long-term occurrence. Further, almost all the respondents experienced satisfactory IAQ during the lockdown period. It is noticeable that before the lockdown enforcement, $\mathrm{X}$-cities experienced the highest poor IAQ, and even during the lockdown, 12\% were not satisfied; this may be a result of very high density built-up and poor ventilation as compared to other cities. For further investigation, the houses surveyed were categorized into well ventilated and poorly ventilated. The categorization was based on two factors, the rating of natural ventilation and the existence of exhausts in the kitchen and washrooms. The ventilation parameters were determined according to the information provided by the building occupant.

The houses, which rated natural ventilation within the satisfactory to excellent range along with exhausts located in both kitchen and toilets, were regarded as well ventilated, whereas the rest were considered as poorly ventilated. As understood in Fig. 7, the X, Y, and Z cities had $70 \%, 72 \%$, and $70 \%$ well-ventilated houses, respectively. Less than $1 \%$ or negligible of these homes reported poor IAQ during the lockdown. On the other hand, 20\%, $17 \%$, and $13 \%$ of well-ventilated homes in cities X, Y, and Z, respectively, described IAQ in their homes as poor before the lockdown when the ambient air pollution was usual. This scenario of poor indoor air reported by well-ventilated homes raises a question on the quality of the indoor 


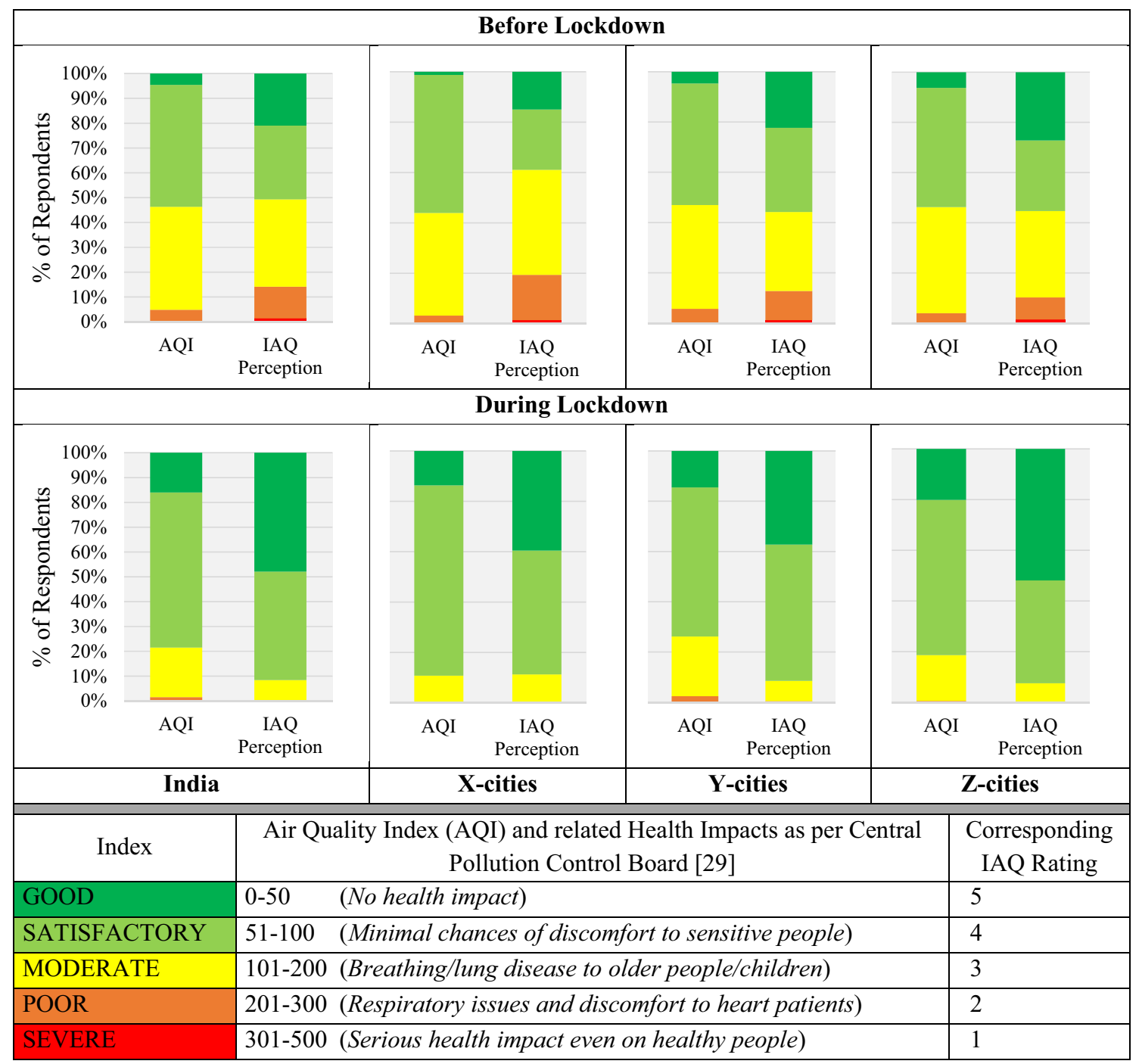

Fig. 6 Comparison of AQI and IAQ perception before and during lockdown

Fig. 7 Ventilation and IAQ perception in the three city categories

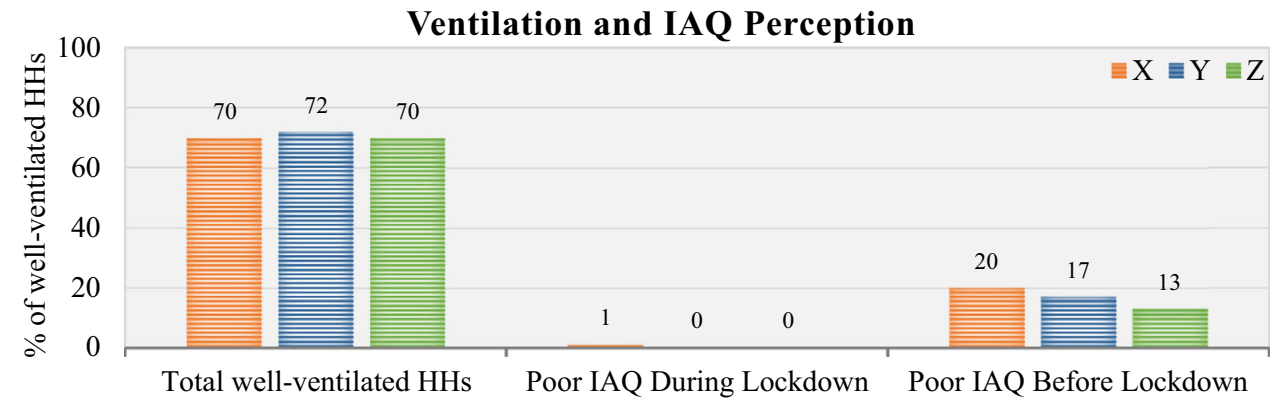

environment. It may point towards the presence of contaminants originating from inside. The following section discusses the existence of outdoor and indoor pollutants.

\section{Perception on IAQ}

The survey participants were enquired about their indoor activities and belongings, which may contribute to IAP; they were also given an opportunity to indicate sources of outdoor air pollution from their vicinity, which affect their indoor environment.

Outdoor and Indoor Pollution Sources

Vehicular traffic, nearby construction site, neighbouring building exhaust, etc., are common outdoor air pollution 
sources. Improperly managed solid waste which commonly constitutes highly decomposable food items, paper, glass, metal objects, old appliances, and plastic can also add to air pollution. Dumping of this garbage in neighbourhood open areas and streets is an unfortunate common view in towns and cities. The waste may keep accumulating into heaps for months or even longer duration, creating health issues by inhalation of toxic gases and providing breeding grounds for microorganism/insect growth. It results in the breaking down of waste with time which mainly produces methane and carbon dioxide, it may also produce ammonia, sulphides, and various other gases depending upon waste composition, accumulation duration and atmospheric conditions. Apart from open dumps, municipal waste burning is a common practice, which may even take place close to residential areas. Municipal waste burning leads to the production of particulate matter, carbon monoxide, sulphur and nitrogen oxides, benzene, etc., which weakens the immune system, irritates lungs and causes respiratory disorders [30]. The participants were encouraged to point out the sources that are present in the close vicinity of their homes, the results are depicted in Fig. 8. For all the three city categories, traffic, construction work, and improperly managed solid waste are the three primary outdoor pollution sources. Traffic pollution is reported by $65 \%, 54 \%$, and $46 \%$ of respondents from X, Y, and $\mathrm{Z}$ cities, respectively. Construction pollution is an issue mainly in $X$-cities reported by $47 \%$ of the participants. Moreover, according to the survey in Y-cities, every one in four houses face problems due to open municipal waste burning, this may be due to ineffective municipal corporation practices, as well as lousy neighbourhoods.

On the other hand, indoor air pollutants vary in level of harmfulness, one of the most dangerous among these is asbestos as it causes cancer. For respondents to recognize the presence of asbestos carcinogen at their residence, two questions were asked. If the participant's house was constructed before the year 2011 (India banned the use of asbestos in the construction industry in 2011) and a white/grey plaster-like covering is visible on pipes at home, this response endorses the presence of asbestos at home. Additionally, the presence of other common indoor pollutants was enquired such as VOCs (indicated if the house is newly constructed without knowledge of paints and varnished used), biological contaminants (indicated by the presence of leaky pipes, visible mould growth, dampness in walls/roof), traditional cooking fuels like coal or wood (common in rural areas), household product fumes, microplastics (indicated by old plastic articles in reuse without inspection of the expiry date or quality of plastic), frequent cigarette smoking indoors, and furry pets present inside. Fig. 9 gives a picture of prominent indoor pollutants in the three city categories. Asbestos may be present in $15 \%, 18 \%$, and $17 \%$ of houses surveyed in $\mathrm{X}, \mathrm{Y}$, and Z-cities, respectively, which is a matter of concern as even after the ban of the material, it may still be in use. On average, $14 \%$ of houses in India have biological contaminants present inside; these can cause not only direct health issues but also facilitate the growth of other pollutants.

Occupants many times unknowingly use products directly emitting dangerous chemical fumes indoors, unaware that they are causing exposure and health risk within their homes. Compounds that break down within a few days' outdoors may last for a long duration in indoor environments. Many common perfumes and fragrances include methylene chloride, toluene, ethyl alcohol, and benzyl chloride which can cause cancers, birth defects, or allergic illnesses. Incense sticks used regularly increase

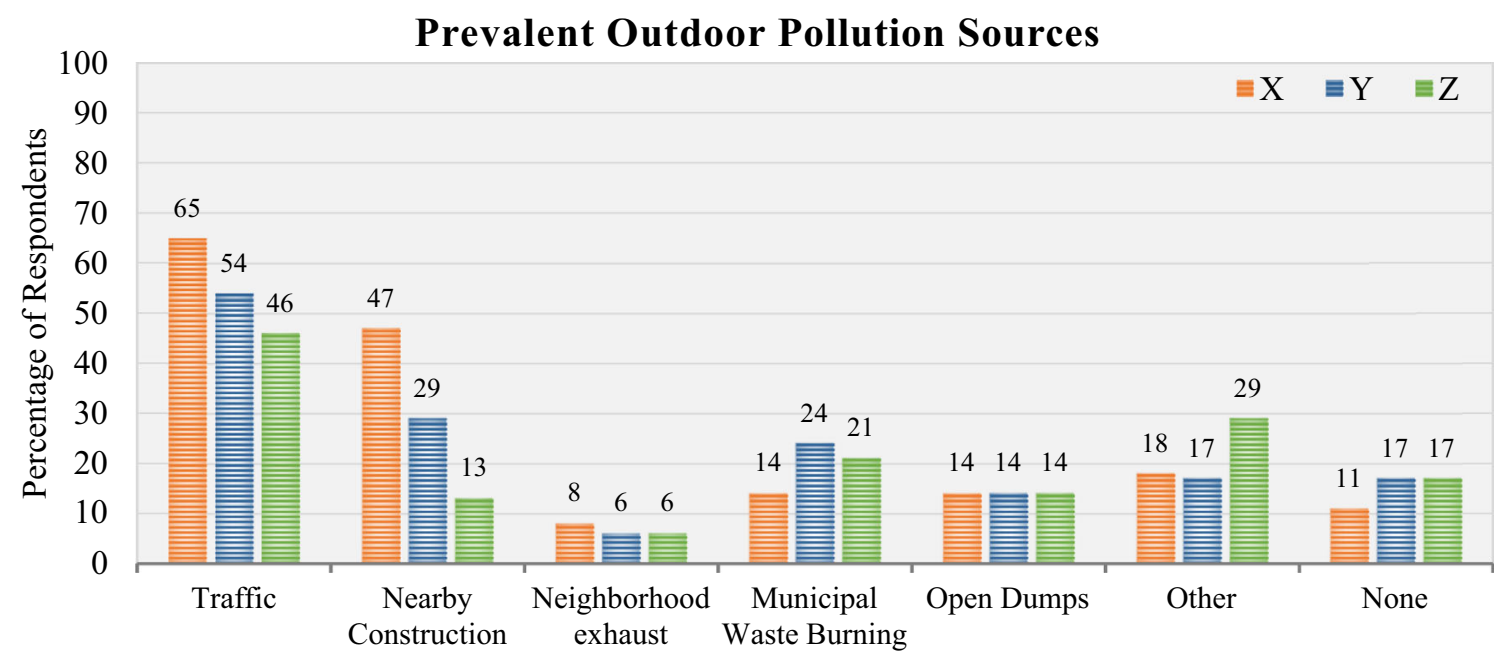

Fig. 8 Prevalent outdoor pollution sources in the three city categories 


\section{Prevalent Indoor Pollution Sources}

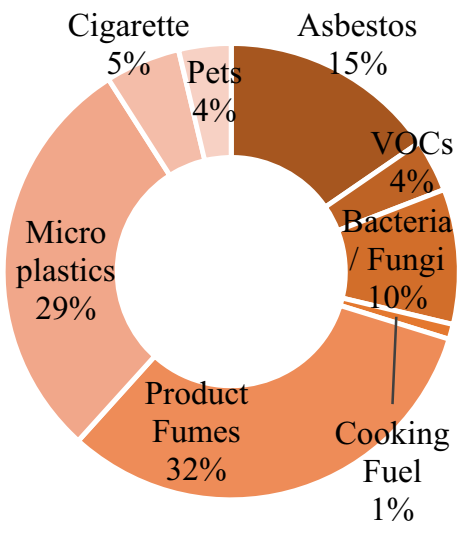

X-cities

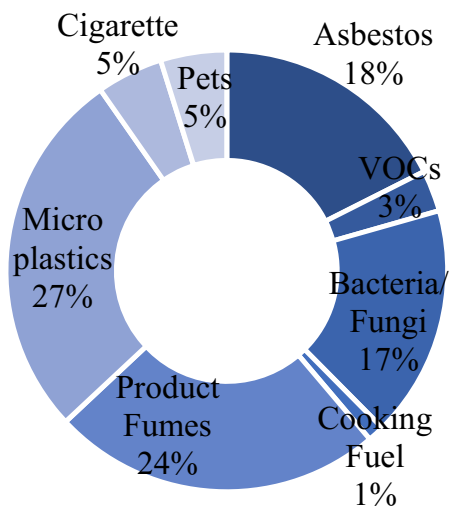

Y-cities

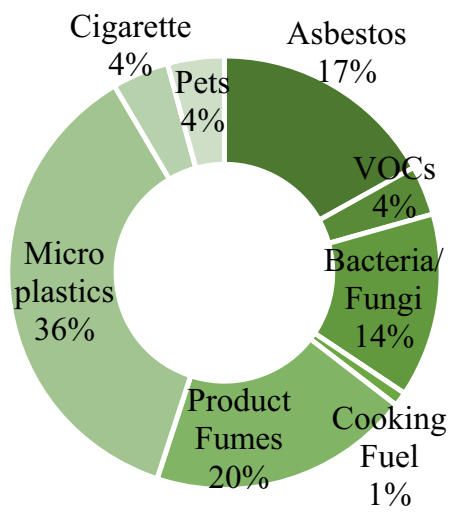

Z-cities

Fig. 9 Prevalent indoor pollution sources in the three city categories

particulate matter concentrations indoors. The most dangerous chemical in personal care products like soaps and facial cleaners is ammonia and its derivatives recognized to have hormone-disturbing effects. Tobacco smoke causes respiratory irritation, bronchitis, pneumonia, lung cancer, and heart diseases. Tobacco smoke, water heaters, and gas stoves are sources of nitrogen dioxide and carbon monoxide. Among others, carbon monoxide attacks haemoglobin in the bloodstream and can even be fatal. The treatment for mites involves toxic pesticides which have shown to obstruct the immune system functioning. This was conveyed to survey participants by the question: "Do you consider the gases released by household products like mosquito repellants, cockroach pesticides, incense sticks, perfumes, water heaters, room fresheners, etc. before buying them? Yes/No". Indoor contamination due to the presence of product fumes like mosquito repellants, incense sticks, perfumes, etc., is indicated to be $32 \%$ in $\mathrm{X}$-cities. In contrast, it is comparatively low in $\mathrm{Y}$ and Z-cities at $24 \%$ and $20 \%$, respectively. On the other hand, awareness of the presence of microplastics in the indoor environment is even lower, and respondents show the least concern while purchasing household products that have the potential to degrade the indoor air quality. In $X$ and Y-cities, 29\% and 27\% of households show the presence of microplastics, respectively. While in small towns or Z-cities, it is even more as $36 \%$ of respondents' point towards the presence of microplastics in their households. This scenario may be due to the abundantly available low-grade plastic articles in small cities and lack of information on the degradation of plastic and its propagation in the surrounding environment.
IAQ-Related Health Issues

Through this section, an effort is made to determine the fraction of people experiencing health issues due to poor indoor air. Common symptoms of indoor air pollution include nausea, fatigue, respiratory problems, asthma, throat infection, difficulty in breathing, fatigue, headache, eye irritation, skin diseases, etc. Since these symptoms can be caused due to multiple health problems, it is difficult to identify the root cause of these symptoms as air contaminants. To counter this, the layered questions or the logic branching technique is used to reach a result systematically. As per ASHRAE, health issues due to IAP can be identified if inhabitants complain about BRI symptoms feel better when moved out of the building. The first question regarding IAQ-related health issues was whether the participant experiences any symptoms related to IAQ as mentioned above at their home, if the participant selected any symptom, the next question enquires whether or not the individual suffers from any health problems that can cause the selected symptoms. If not then it is more likely that it is due to IAP, the next question enquires if these symptoms tend to go away within an hour of going out, if yes, then these were counted as participants with health issues related to IAQ, and the rest were not. The three-tier questions lead to a very small fraction of respondents experiencing BRI with reduced bias and increased level of confidence.

The total number of participants with health issues related to IAQ from X, Y, and Z-cities is 18,18 , and 17 , respectively. Overall, only 53 out of 1015 respondents could confidently say the health issues they face are a result of poor IAQ. As shown in Fig. 10, IAQ-related health issues are experienced more by males than females; also, the age group between 26 and 35 reports most such matters. 

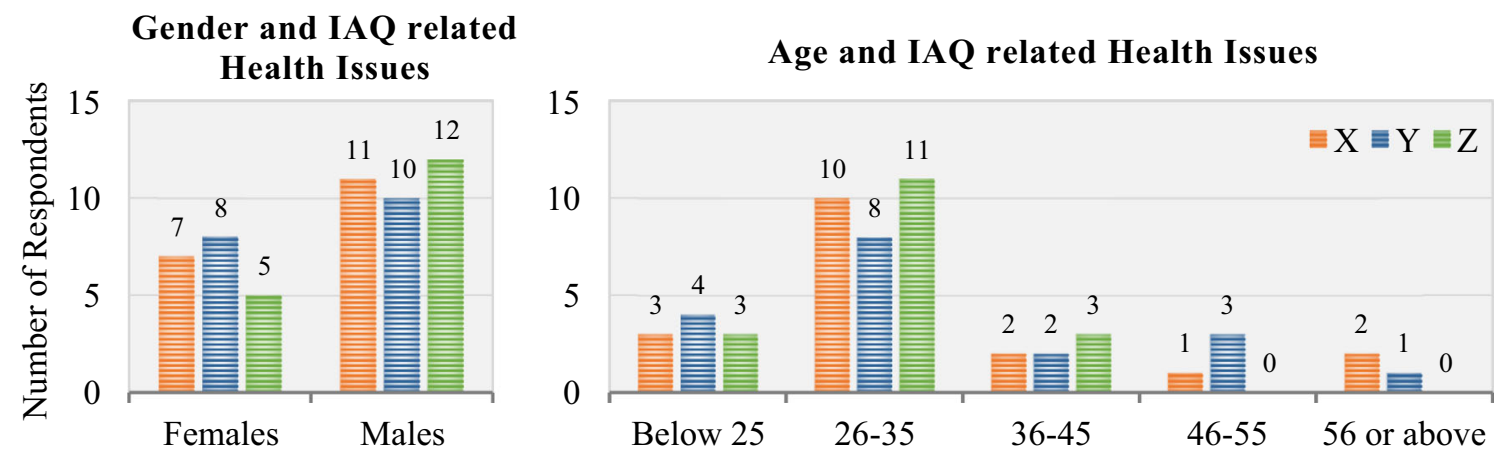

Fig. 10 IAQ-related health issues and gender and age of respondents

A detailed study of this matter is further required. In Sect. $6.1,20 \%, 17 \%$, and $13 \%$ of well-ventilated homes in cities $\mathrm{X}, \mathrm{Y}$, and $\mathrm{Z}$, respectively, described IAQ in their homes as poor before the lockdown when the ambient air pollution was usual, raising questions on the indoor environment and the presence of contaminants originating from inside.

This was further analysed by assessing the experience of IAQ-related health problems in the two categories of houses. As shown in Fig. 11, participants from 25 wellventilated homes in X-cities and 12 and 9 from $\mathrm{Y}$ and Z-cities experienced IAQ-related health issues. For further investigation on the effect of ventilation (independent variable) on IAQ-related health issues or BRI (dependent variable), a parametric statistical method z-score was used to handle the categorical (nominal) data type assuming a normal distribution. Since $n>30, t$ tests would not produce reliable results, therefore, the $\mathrm{z}$-score is used with a significance level of 0.05. For the score formula in Fig. 11, $\mathrm{x}$ represents the raw score value of BRI, $\mu$ is the mean, and $\sigma$ is the standard deviation. The null hypothesis means that the independent variable did not have any effect on the dependent variable. Since a p value of less than 0.05 is obtained, it is statistically significant to indicate strong evidence against the null hypothesis, indicating an effect of ventilation on IAQ-related health issues.
IAQ Awareness

This scenario brings attention to awareness and mindfulness towards IAQ in urban areas. To assess this, firstly, the participants were enquired about their cleaning activities. Based on the frequency of dusting, sweeping, and mopping, the participants who clean regularly are identified. Secondly, consideration practice of air emissions of articles like incense sticks (typically used in religious rituals), pesticides, perfumes, etc., was enquired. As per research on the distribution of airborne microplastics (size $<5 \mathrm{~mm}$ ) in dust and their human exposure, microplastics were detected at higher concentrations indoor than outdoor in most studies in urban areas [31]. It can be inferred that the concentrations are higher indoors because, during material weathering, plastic product shed microplastics, especially low-quality plastic products which are extensively used and reused in Indian households. The study of airborne microplastics began only in 2016 [32] and currently, there are no standard operation protocols for the analysis of microplastics in indoor air. Thus thirdly, the participants were asked if they checked the expiry date of plastic articles like bottles and cans before reusing. Fourthly, ownership of air purifier, IAQ monitor, and indoor plants was interrogated. In the last section on awareness or concern regarding IAQ, the respondents were asked if they felt

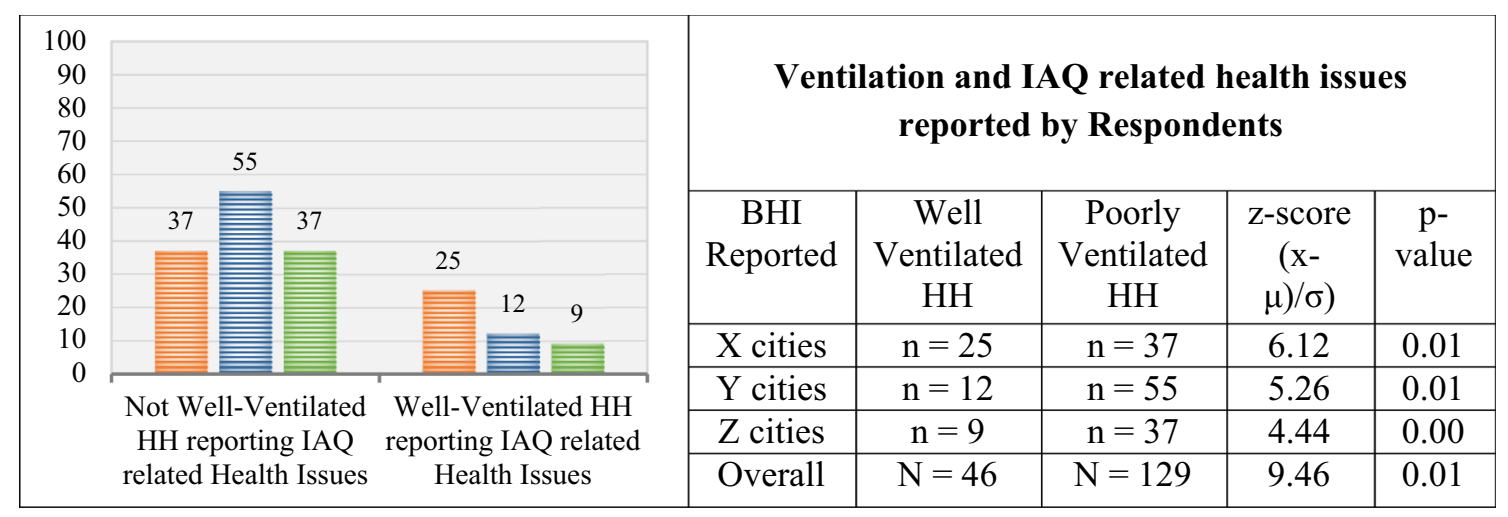

Fig. 11 Ventilation and IAQ-related health issues in the three city categories 


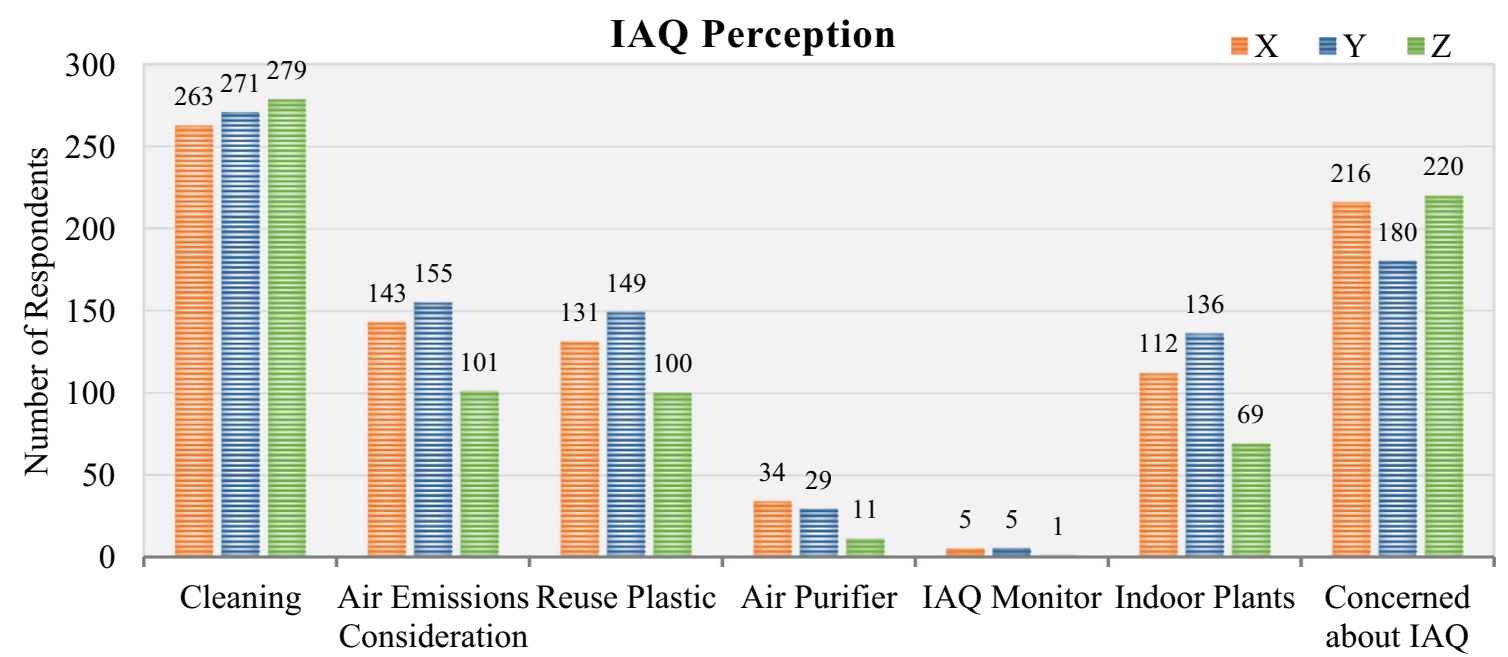

Fig. 12 IAQ perception in the three city categories

concerned about the air inside their homes when shown a picture depicting the following: pollutants, moulds, and bacteria; chemicals from cleaning products; cigarette smoke containing around 4,000 chemicals; animal hair; carbon monoxide fumes from an attached garage; chemicals released from modern building furnishing materials; combustion gases from wood-burning stoves and chemical fumes from paints \& solvents. The results of these questions are depicted in Fig. 12.

Participants from all cities give regular cleaning supreme importance, whereas broadly, only one-fifth of the participants in the three category cities are concerned about fumes from household products and microplastics. As evident from the figure above, air-purifiers are installed by a small fraction of people, whereas IAQ-monitoring devices are negligible. Indoor plants' popularity in Y-cities is more than X-cities; this may be due to the available carpet area. Overall, about $60 \%$ of the respondents in all city types were concerned about the IAQ of their homes after observing pictures of various air pollutants.

\section{Relationship Between Various Parameters and Perceived IAQ}

Pearson's correlation method is adopted to assess the relationship between distance from the main road, ventilation, indoor and outdoor air pollution, and occupant perceptions of IAQ before and during the lockdown. A protocol of lower weightage indicating "bad for IAQ" and higher weightage indicating "good for IAQ" has been followed for every parameter. Perceived IAQ has been rated from 1 , meaning very poor, to 5 , as very good. For reporting the distance from the main road, a few minutes' walk is indicated by 1 and a distance of $1 \mathrm{~km}$ or more is indicated by 5 . The floor level, if 21 or above, is indicated by value 1 as higher the level, less would be the pollution, giving the uppermost value to the ground floor. Ventilation is rated as 1 if the house feels mostly stagnant or a fan is needed all the time and 5 when fresh outside air circulates thoroughly in the home. To compute outdoor and indoor pollution levels, weightage to each pollutant is provided according to its health impact severity and then combined to obtain the final value. Weightage for the outdoor pollutants in descending order is as follows: nearby construction site-10, traffic - 8, garbage burning - 6, garbage heaps nearby-5, others-4, neighbouring building exhaust -3 , and none -0 . Similarly, for indoor sources, the weights are as follows, asbestos-10, smoking-10, cooking fuel-7, furry pets-6, leaky pipes/roof/mould growth-5, air emissions of products -5 , and reuse of plastic articles without checking expiry-2. Moreover, negative weights are assigned to air cleansing articles, air purifiers $(-5)$, and indoor plants $(-3)$. The questionnaire mentioned that the indoor plant's presence should be marked only if they are significant in number. The $R^{2}$ values of Pearson's correlation analysis are tabulated as follows.

Pearson's correlation is a parametric measure of correlation that indicates both the strength and direction of the relationship between a pair of variables based on the method of covariance. It is anticipated that higher correlation coefficient values imply a stronger correlation. If the degree of the correlation value is near \pm 1 , then it said to be a perfect correlation: as one variable increases, the other variable also tends to increase (if positive) or decrease (if negative). If the coefficient value lies between \pm 0.50 and \pm 1 , then it is said to be a strong correlation. If the value lies between \pm 0.30 and \pm 0.49 , then it is said to be a medium correlation. When the value lies below +0.29 , then it is said to be a small correlation. And, the value is 
Table 2 Relationship between various parameters and perceived IAQ

\begin{tabular}{|c|c|c|c|c|c|c|c|c|}
\hline \multicolumn{6}{|c|}{ All respondents } & \multicolumn{3}{|c|}{ BRI respondents } \\
\hline IAQ & Road buffer & Floor level & Ventilation & Outdoor pollution & Indoor pollution & Ventilation & Outdoor pollution & Indoor pollution \\
\hline \multicolumn{9}{|l|}{ India } \\
\hline Before & 0.16 & 0.1 & 0.2 & -0.17 & -0.00 & 0.49 & -0.29 & $-0.25(15)$ \\
\hline During & 0.03 & 0.05 & 0.3 & -0.03 & -0.04 & 0.16 & -0.03 & -0.00 \\
\hline \multicolumn{9}{|l|}{ X-cities } \\
\hline Before & 0.1 & 0.01 & 0.1 & -0.18 & -0.08 & 0.34 & -0.28 & $-\mathbf{0 . 3 5}(25)$ \\
\hline During & 0.1 & 0.01 & 0.2 & -0.09 & -0.05 & 0.33 & -0.05 & -0.08 \\
\hline \multicolumn{9}{|l|}{ Y-cities } \\
\hline Before & 0.1 & 0.1 & 0.2 & -0.18 & -0.05 & 0.53 & -0.27 & $-0.18(08)$ \\
\hline During & 0.00 & 0.01 & 0.3 & -0.04 & -0.07 & 0.15 & -0.08 & -0.07 \\
\hline \multicolumn{9}{|l|}{ Z-cities } \\
\hline Before & 0.3 & 0.05 & 0.1 & -0.14 & -0.06 & 0.34 & -0.27 & -0.1 \\
\hline During & 0.02 & 0.06 & 0.3 & -0.04 & -0.05 & 0.012 & -0.19 & -0.03 \\
\hline
\end{tabular}

zero points towards no correlation. As evident from Table 2, the analysis is carried out for all respondents and then exclusively for only those respondents who reported building-related illness (BRI). The correlation is found to be trivial in the case of all respondents. The outdoor and indoor pollution show a negative association with perceived IAQ as an increase in pollution will decrease the indoor satisfaction level. Although in the case of BRI respondents, a unique relationship is observed between perceived indoor air quality and ventilation before the lockdown period when air pollution was at its normal state. The $R^{2}$ values for $\mathrm{X}$ and $\mathrm{Z}$-cities are 0.34 ; in contrast, the strongest correlation value is observed as 0.53 for Y-cities. Furthermore, the $\mathrm{R}^{2}$ value of -0.35 between indoor air perception before lockdown and indoor pollution levels in $\mathrm{X}$-cities may indicate poor ventilation and the presence of indoor originated pollutants in metro cities, a critical examination of such cases is required.

\section{Conclusion}

Ironically, the COVID-19 health crisis has incidentally provided a solution to a different health crisis, i.e. pollution. The data analysis and comparison of time before enforcement of restrictions and during the lockdown have revealed that the lockdown has caused substantial improvement in air quality countrywide, both outdoors and indoors. Almost all the respondents experienced satisfactory IAQ during the lockdown period. It is noticeable that before the lockdown enforcement, X-cities experienced the highest poor IAQ, and even during the lockdown, $12 \%$ were not satisfied; this may be a result of very high density built-up and poor ventilation as compared to other cities. Traffic pollution is reported as the most prevalent outdoor pollutant by $65 \%, 54 \%$, and $46 \%$ of respondents from $\mathrm{X}, \mathrm{Y}$, and $\mathrm{Z}$ cities, respectively. Construction pollution and improper municipal waste management are also a major concern, especially in small cities. Indoor contamination due to the presence of product fumes like mosquito repellants, incense sticks, perfumes, etc., is indicated to be $32 \%$ in $\mathrm{X}$-cities. In contrast, it is comparatively low in $\mathrm{Y}$ and Z-cities at $24 \%$ and $20 \%$, respectively. In $\mathrm{X}$ and Y-cities, $29 \%$ and $27 \%$ of households show the presence of microplastics, respectively. While in small towns or Z-cities, it is even more as $36 \%$ of respondents' point towards the presence of microplastics in their households. This could be due to a lack of awareness among the citizens. Moreover, the presence of asbestos is indicated in $15 \%$, $18 \%$, and $17 \%$ of houses surveyed in $\mathrm{X}, \mathrm{Y}$, and Z-cities, respectively, which is a matter of grave concern both in terms of public health and law enforcement. While the study further evaluates the association of various related parameters with reported IAQ, a significant relationship of ventilation with BRI or perceived IAQ is observed through two inferential statistical techniques. The parametric $\mathrm{z}$-score investigation gives a $\mathrm{p}$ value of 0.01 , statistically significant to point towards an effect of ventilation on IAQrelated health issues. Also, through Pearson's correlation, a unique relationship is observed between perceived IAQ and ventilation before the lockdown period when air pollution was at its normal state. The $\mathrm{R}^{2}$ values for $\mathrm{X}$ and $\mathrm{Z}$-cities are 0.34 ; in contrast, the strongest correlation value is observed as 0.53 for Y-cities. Furthermore, the $R^{2}$ value of -0.35 between indoor air perception before lockdown and indoor pollution levels in $\mathrm{X}$-cities may indicate poor ventilation and the presence of indoor originated pollutants in metro cities, a critical examination of such cases is required. However, this is a temporary state, as the pollution levels will rise again after the lockdown is lifted as India is 
undergoing rapid expansion of cities and economic growth [33]. The pandemic resulted in work from home schemes and increased acceptance of distance learning, online entertainment, and shopping. A large population spending more time indoors in various house types has raised questions on existing indoor inhabitation conditions. Studies on the indoor environment from the past two decades show that the presence of indoor contaminants is higher than expected, and contaminants identified are unlike those outside. In recent times, knowledge about the contaminants present in indoor air, their sources, and the factors contributing to a decline in IAQ have increased, though there is much more to be studied in the field. With degrading IAQ in India and its association with sickness and mortality, the need is to assess the exposure levels, proper designing, effective preventive measures, and dedication to promote a healthy lifestyle.

Funding Not applicable.

Availability of Data and Material Not applicable.

\section{Declarations}

Conflict of interest The authors declare that they have no conflict of interest.

Software Code Availability Not applicable.

\section{References}

1. R. Singh, WHO Confirms COVID-19 can be Airborne. Retrieved from inventive (2020).

2. P. Chatterjee, Indian air pollution: loaded dice. Lancet Planet. Health III, 26-39 (2019)

3. M.Z. Shubham Sharma, Effect of restricted emissions during COVID-19 on air quality in India. Sci. Total Environ. (2020). https://doi.org/10.1016/j.scitotenv.2020.138878

4. Earth Observatory NASA, Airborne Particle Levels Plummet in Northern India. Retrieved from Earth Observatory NASA. Retrieved from https://earthobservatory.nasa.gov/images/146 596/airborne-particle-levels-plummet-in-northern-india (2020)

5. R.C. Saidur Rahaman, COVID-19's lockdown effect on air quality in Indian cities using air quality zonal modeling. Urban Clim. (2021). https://doi.org/10.1016/j.uclim.2021.100802

6. S.M. Sunil Gulia, COVID 19 lockdown-air quality reflections in Indian Cities. Aerosol Air Qual. Res. 1, 21 (2021). https://doi.org/10.4209/aaqr.200308

7. A.L. Sonal Kumari, COVID-19 and air pollution in Indian cities world's most polluted cities. Aerosol Air Qual. Res. Special Issue COVID-19 Aerosol Drivers Impacts Mitig. 8, 2592-2603 (2020). https://doi.org/10.4209/aaqr.2020.05.0262

8. P.C. Jay Saha, Indoor air pollution (IAP) and pre-existing morbidities among under-5 children in India: are risk factors of coronavirus disease (COVID-19)? Environ. Pollut. (2020). https://doi.org/10.1016/j.envpol.2020.115250

9. P.W. Anne Steinemann, Ten questions concerning green buildings and indoor air quality. Build. Environ. 112, 351-358 (2017)
10. Velux, The disturbing facts about the indoor generation. Retrieved July 15, 2019, from https://www.velux.com/ind oorgeneration (2018)

11. X.G. Solá, Indoor air quality: introduction, in Encyclopedia of Occupational Health and Safety, 4th edn., ed. by X.G. Solá (The International Labour Office, New York, 2012)

12. C.P. Schiavon, Indoor Environmental Quality Surveys. A Brief Literature Review. Indoor Environmental Quality (IEQ) (2011)

13. World Health Organization, Health and sustainable development-Indoor air quality risks. Retrieved from https://www.who.int/sustainable-development/housing/healthrisks/indoor-air-quality/en/ (2019)

14. ANSI/ASHRAE 62.2, Ventilation and Acceptable Indoor Air Quality in Residential Buildings. 2019: Americal National Standards Institute (2019)

15. P.W. Yuexia Sun, Indoor Air Pollution and Human Perception in Public Buildings in Tianjin, China. Sci. Direct 552-557 (2015)

16. D. Michael, J.J. Lebowrtz, The new standard environmental inventory questionnaire for estimation of indoor concentrations. JAPCA (1989). https://doi.org/10.1080/08940630.1989.10 466633

17. A.K. Vinita Katiyar, Characterization of Indoor Air Quality. National Seminar on Spatial Dimensions of Environmental Problems and Natural Resources Law ICSSR (IMPRESS). Karnal: Indira Gandi National Open University (IGNOU) (2019).

18. Ministry of Statistics and Programme Implementation, Periodic Labour Force Survey, July 2017-June 2018 Annual Report. Delhi: National Statistical Office, Government of India (2019).

19. D.E.V.S. Kiran Kumar, Formaldehyde monitoring in office buildings located in tropical climates of India. Mater. Sci. Eng. IOP Publishing (2019)

20. Tata Consultancy Services Limited, TCS Worldwide. Retrieved from tcs.com (2020)

21. Business Today, Post-COVID, $75 \%$ of 4.5 lakh TCS employees to permanently work from home by ' 25 , from $20 \%$. Retrieved from Business Today: https://www.businesstoday.in/current/cor porate/post-coronavirus-75-percent-of-3-5-lakh-tcs-employeespermanently-work-from-home-up-from-20-percent/story/ 401981.html(2020)

22. Ministry of Environment, Forest, and Climate Change, Year-End Review: Ministry of Environment, Forest, and Climate Change. New Delhi: Government of India (2020)

23. The Economic Times, Not just outdoor, indoor air in Delhi polluted too: Study. Retrieved from The Economic Times: https://economictimes.indiatimes.com/news/politics-and-nation/ not-just-outdoor-indoor-air-in-delhi-polluted-too-study/ articleshow/71279705.cms?from $=$ mdr (2019)

24. J. Nandi, Air pollution killed the highest number of under 5 children in India in 2016: WHO Report. Retrieved from https://www.hindustantimes.com/india-news/air-pollution-killedhighest-number-of-under-5-children-in-india-in-2016-whoreport/story-wyhYB6EO1Qg8VW1MM1L3PO.htmlSridhar (2018)

25. N. Sreedhar, Indoor Air Pollution: The invisible adversary. Retrieved from https://www.livemint.com/mint-lounge/featur es/indoor-air-pollution-the-invisible-adversary-1567759328936.h tml (2019)

26. Government of India, Ministry of Finance. Office Memorandum 2/5/2014-E.II(B). New Delhi, India (2015)

27. CPCB, Operating Stations under the National Air Quality Monitoring Programme (NAMP) (2019)

28. Central Pollution Control Board, National Air Quality Index. Delhi: MOEFCC Government of India (2014)

29. Central Pollution Control Board, IMPACT OF LOCKDOWN (25th March to 15th April) ON AIR QUALITY. Ministry of 
Environment, Forest and Climate Change. Delhi: Govt. of India (2020)

30. National Health Portal India, Solid waste and its management. Retrieved from NHP Government of India: https://www. nhp.gov.in/solid-waste_pg (2019)

31. J.L. Chunguang Liu, Widespread distribution of PET and PC microplastics in dust in urban China and their estimated human exposure. Environ. Int. 21, 116-124 (2019)
32. A.W. Christian Ebere Enyoh, Airborne microplastics: a review study on a method for analysis, occurrence, movement and risks. Nature 651-668 (2019)

33. N. Khan, An Exploratory study of impact of lockdown on air quality of Delhi. Delhi, India (2020)

Publisher's Note Springer Nature remains neutral with regard to jurisdictional claims in published maps and institutional affiliations. 